\title{
Promoção da saúde mental: o atendimento de adolescentes com sintomas depressivos em uma clínica-escola
}

\author{
Promotion of mental health: care for adolescents with depressive symptoms in a school clinic \\ Promoción de la salud mental: la atención de adolescentes con síntomas depresivos en una clínica \\ escolar
}

Recebido: 20/01/2022 | Revisado: 27/01/2022 | Aceito: 02/02/2022 | Publicado: 04/02/2022

Daniela Souza da Silva

ORCID: https://orcid.org/0000-0001-8786-4458 Universidade Luterana do Brasil, Brasil E-mail: danielasouzadasilva@gmail.com

Nádia Teresinha Schröder

ORCID: https://orcid.org/0000-0001-5505-1137 Universidade Luterana do Brasil, Brasil

E-mail: nadia.schroder@ulbra.br

Dóris Cristina Gedrat

ORCID: https://orcid.org/0000-0002-5660-1775 Universidade Luterana do Brasil, Brasil

E-mail: doris.gedrat@ulbra.br

\begin{abstract}
Resumo
Os adolescentes formam um grupo vulnerável quanto ao desenvolvimento de alguns transtornos psicológicos, dentre eles a depressão, cuja importância dos atendimentos em saúde mental desse público é reconhecida. Este estudo teve como objetivo identificar a percepção dos adolescentes com sintomas depressivos quanto aos benefícios do atendimento recebido em uma clínica-escola que oferece serviços psicológicos na cidade de Manaus-AM. É uma pesquisa com abordagem qualitativa na qual participaram 10 adolescentes na faixa etária de 15 a 18 anos de idade atendidos em 2020 e 2021. Os dados coletados nas entrevistas semiestruturadas foram analisados de acordo com a análise de conteúdo temática. Os benefícios identificados foram: aumento da autoestima; benefícios no relacionamento familiar; benefícios durante a pandemia de COVID 19; diminuição/ausência da autolesão e de outros sintomas. Esses benefícios podem não significar uma remissão total dos sintomas depressivos, porém houve mudanças positivas na qualidade de vida dos adolescentes.
\end{abstract}

Palavras-chave: Adolescência; COVID 19; Depressão; Psicoterapia; Suicídio.

\begin{abstract}
Adolescents form a vulnerable group to develop some psychological disorders, including depression, and the importance of mental health care for this public is recognized. This study aimed to identify the perception of adolescents with depressive symptoms regarding the benefits of care at a teaching clinic that offers psychological services in the city of Manaus-AM. This research has a qualitative approach in which 10 adolescents aged between 15 and 18 years old attended in 2020 and 2021 participated. Data collected in semi-structured interviews were analyzed according to thematic content analysis. The benefits identified were: increased self-esteem; benefits in the family relationship; benefits during a COVID 19 pandemic; decrease/absence of self-injury and other symptoms. These benefits may not mean a total remission of depressive symptoms, but there was a positive change in the adolescents' quality of life.
\end{abstract}

Keywords: Adolescent; COVID 19; Depression; Psychotherapy; Suicide.

\section{Resumen}

Los adolescentes forman un grupo vulnerable en cuanto al desarrollo de algunos trastornos psicológicos, entre ellos la depresión, cuya importancia en la atención de la salud mental para este público es reconocida. Este estudio tuvo como objetivo identificar la percepción de los adolescentes con síntomas depresivos sobre los beneficios de la atención recibida en una clínica docente que ofrece servicios de psicología en la ciudad de Manaus-AM. Se trata de una investigación con enfoque cualitativo en la que participaron 10 adolescentes con edades entre 15 y 18 años atendidos en los años 2020 y 2021. Los datos recolectados en entrevistas semiestructuradas fueron analizados de acuerdo con el análisis de contenido temático. Los beneficios identificados fueron: aumento de la autoestima; beneficios en la relación familiar; beneficios durante la pandemia de COVID 19; disminución/ausencia de autolesiones y otros síntomas. Estos beneficios pueden no significar una remisión completa de los síntomas depresivos, pero hubo cambios positivos en la calidad de vida de los adolescentes.

Palabras clave: Adolescencia; COVID 19; Depresión; Psicoterapia; Suicidio. 


\section{Introdução}

A adolescência é uma etapa do desenvolvimento humano que se inicia aos 10 anos e se estende até os 19 anos de idade, segundo Organização Mundial da Saúde (OMS, 2014), e de acordo com o Estatuto da Criança e do Adolescente-ECA (Lei $n^{\circ} 8.069,1990$ ), que trata sobre a proteção integral da Criança e do Adolescente diante da lei, a adolescência começa aos 12 anos, estendendo-se até os 18 anos de idade. Essa fase é caracterizada por mudanças biológicas trazidas pela puberdade, além de mudanças psicológicas, como a construção da identidade e da autoestima, e mudanças sociais, como o envolvimento em grupos e a busca pela autonomia (Henriques, 2018).

A fase da adolescência pode ser considerada conturbada levando em conta as mudanças ocorridas, como físicas, sociais, refletindo consequentemente na esfera psicoafetiva desse grupo (Grolli, 2017). Entende-se que os adolescentes formam uma população vulnerável a apresentar comportamentos de risco, como o uso de drogas, e a desenvolver alguns transtornos, como os alimentares, de conduta, a depressão, dentre outros, sendo reconhecida a necessidade de dar atenção à saúde mental desse grupo (Just \& Enumo, 2015).

Acerca da depressão, o Manual de Diagnóstico e Estatístico de Transtornos Mentais-DSM-5 (American Psychiatric Association-APA, 2014) a identifica como um transtorno de humor, com sintomas físicos como alterações no sono, agitação, fadiga e com sintomas psíquicos, como pensamentos negativos, apatia, sentimento de culpa. No caso dos adolescentes, os sintomas depressivos podem se apresentar de forma atípica, como na constância do tédio, na busca pelo isolamento social, no cansaço físico e mental, na insatisfação com o corpo, no aumento ou na diminuição do apetite e/ou do sono, na presença de medos e ansiedades, nos comportamentos suicidas e outros sintomas (Müller \& Silva, 2017).

O Relatório Mundial de Saúde da Organização Mundial de Saúde (OMS, 2002) já alertava acerca do suicídio como uma consequência dos sintomas depressivos, trazendo uma apreensão quanto ao aumento dos casos no futuro. E o relatório de Prevención de la Conducta Suicida elaborado pela Organização Pan-Americana da Saúde (OPAS, 2016) destaca que a segunda causa de morte dos jovens de 15 a 29 anos de idade em todo o mundo é o suicídio, tendo como um dos principais fatores os transtornos como a depressão, dentre outros do âmbito psicoafetivo.

Embora os sintomas depressivos estejam presentes em grande parte da população, eles não são identificados e tratados como problemas psicológicos, ou seja, em muitos casos, os sintomas como cansaço, distúrbios de sono e de apetite, dentre outros sintomas físicos, são investigados como um problema de ordem orgânica apenas (Brito et al, 2015; Pinto et al, 2018). Além disso, estudos trazem que cerca de $70 \%$ dos adolescentes com sintomas depressivos não recebem qualquer tratamento, refletindo na qualidade de vida desse público (Bonin \& Moreland, 2012; Pinto et al, 2018).

Com a criação do Estatuto da Criança e do Adolescente (ECA) e dos Centros de Atenção Psicossociais (CAPS), no final do século XX, com destaque para os Centros de Atenção Psicossociais Infantojuvenis (CAPSij), voltados ao atendimento de crianças e adolescentes, houve um trabalho direcionado à saúde e proteção desse público, incluindo sua saúde mental (Galhardi \& Matsukura, 2018). Nesse contexto, os profissionais de saúde mental são primordiais na identificação dos sinais e sintomas de problemas psicológicos no público adolescente, assim como na oferta do tratamento apropriado aos mesmos (Grolli, 2017; Thapar et al, 2012).

Acerca do tratamento dos adolescentes com sintomas depressivos, as clínicas-escola de psicologia, que fazem parte das Instituições de Ensino Superior, tem um papel importante no alcance desse público, já que é oferecido um serviço de psicoterapia para a comunidade, beneficiando a população, além de consolidar a representação social do psicólogo (Silvares, 2006). As psicoterapias realizadas nas clínicas-escola podem ser baseadas em diversas abordagens psicológicas, dentre elas as psicoterapias breves, com um tempo limitado, indicada para conflitos ou sintomas pontuais, focais (Cordiolli et al, 2018). Nas psicoterapias breves, o número de sessões pode variar de acordo com o julgamento clínico em cada caso, com evidências de benefícios no limite de 7 a 40 sessões (Lemgruber, 2008). 
As intervenções psicoterápicas na fase da adolescência são uma possibilidade para a elaboração do sofrimento psicoafetivo presente nesse momento, contribuindo para o entendimento das demandas dos adolescentes e do seu desenvolvimento emocional (Benetti et al, 2017). E, ainda, considerando o aparecimento do Coronavírus (COVID 19), no final de 2019, declarado como pandemia pela Organização Mundial da Saúde (OMS), os serviços psicológicos passaram a ter uma grande procura devido aos fatores que surgiram com essa realidade vivida pelo mundo, como as questões da doença em si, as perdas (familiares, econômicas), o isolamento social, alteração no cotidiano e outros fatores (Oliveira, 2020). Desse modo, com o surgimento da pandemia, os adolescentes, assim como a população como um todo, ficaram expostos a um risco maior de apresentar sintomas depressivos, ansiedades, fobias e outras questões de ordem psicológica (Oliveira, 2020).

Assim, este estudo foi direcionado aos adolescentes que apresentam sintomas depressivos e que foram atendidos em uma clínica-escola que oferece serviços psicológicos na cidade de Manaus-AM. Tendo como objetivo geral identificar a percepção dos adolescentes quanto aos benefícios do atendimento recebido, referentes ao acolhimento e à escuta, e como objetivos específicos: relacionar os sintomas depressivos dos adolescentes; verificar a relação dos aspectos de melhoras dos adolescentes e o atendimento na clínica-escola; verificar os benefícios do atendimento na clínica-escola relacionados ao período da pandemia de Covid 19.

Este estudo é relevante na medida em que traz uma visão sobre a percepção dos adolescentes com sintomas depressivos acerca do atendimento psicológico recebido, considerando ainda o momento de pandemia em que se está vivendo. Além disso, os resultados da pesquisa poderão servir para chamar a atenção para a importância dos serviços de saúde mental voltados ao público adolescente, principalmente à comunidade com menos acesso a esse tipo de atendimento, tendo como exemplo as clínicas-escola.

\section{Metodologia}

Este estudo tem uma abordagem qualitativa, descritiva, que, segundo Minayo (2014), trabalha no âmbito particular dos significados, das motivações e das aspirações pessoais, além de trabalhar com as crenças, valores e atitudes que não podem ser quantificadas. A pesquisa ocorreu em uma clínica-escola ligada a uma Instituições de Ensino Superior particular na cidade de Manaus-AM, e que oferece, dentre outros serviços, o atendimento psicológico voltado a Psicoterapia Focal Breve.

Participaram deste estudo 10 adolescentes na faixa etária de 15 a 18 anos de idade, selecionados através de prontuários, com o critério de terem sido atendidos nos anos de 2020 e 2021 na clínica-escola, com pelo menos oito sessões de psicoterapia. Sendo que a maioria dos participantes seguiram em atendimento psicoterápico após a realização da pesquisa. Os critérios de exclusão foram: adolescentes impossibilitados de conceder a entrevista no período estipulado na pesquisa e aqueles cujo os pais ou os responsáveis não demonstraram interesse na participação dos adolescentes na pesquisa.

A coleta de dados se deu a partir de entrevistas semiestruturadas, ocorridas no mês de junho de dois mil e vinte e um, que seguiram um roteiro com perguntas elaboradas previamente, no qual incluíam-se os dados sociodemográficos, como idade, sexo, escolaridade e também questões que abordavam as razões para a busca do tratamento na clínica-escola, o histórico dos sintomas de depressão e a percepção quanto aos benefícios da escuta e acolhimento na clínica-escola. Os participantes tinham a opção de conceder a entrevista de forma presencial ou online, mas todos os participantes optaram pelo formato online, com dia e hora previamente combinados. Mesmo as entrevistas ocorrendo de forma online, elas foram realizadas em local reservado, a fim de assegurar a privacidade e a confidencialidade das informações, com duração média de 40 minutos.

Os dados obtidos através das questões sociodemográficas foram apresentados em forma de tabela. Os dados qualitativos obtidos pelas demais perguntas foram analisados de acordo com a análise de conteúdo na modalidade temática de Minayo (2014). Segundo a autora, essa análise é subdividida em: ordenação, classificação e análise dos dados.

Os participantes foram identificados neste estudo através de nomes fictícios acompanhados do número referente à 
respectiva idade, preservando, assim, o seu anonimato. O estudo foi aprovado sob o parecer CAAE $\mathrm{n}^{\mathrm{o}}$ 35620620.9.0000.5349, após ser submetido à avaliação do Comitê de Ética em Pesquisa em Seres Humanos da Universidade Luterana do Brasil.

\section{Resultados}

\subsection{Perfil dos participantes}

Os adolescentes entrevistados tinham em média 16,5 anos de idade, com predominância do sexo feminino (90\%) e cursando o ensino médio (70\%). A maior parte dos adolescentes pertence a famílias de classe baixa (70\%), com uma configuração familiar formada por: mãe, pai e irmãos ou não (20\%); mãe, padrasto e irmãos ou não (40\%); mãe e irmãos ou não (40\%). Alguns adolescentes (40\%) destacaram que estão ou estiveram em acompanhamento psiquiátrico e a maioria (70\%) relatou ter algum familiar (pais, irmãos, tios e/ou avós) com diagnóstico de depressão. Os dados dos participantes são observados na Tabela 1.

Tabela 1: Dados dos participantes.

\begin{tabular}{lc}
\hline \multicolumn{2}{c}{ Adolescentes com sintomas depressivos (n=10) } \\
\hline Variáveis & Participantes (\%) \\
\hline Idade & 30 \\
15 anos & 20 \\
16 anos & 20 \\
17 anos & 30 \\
18 anos & \\
\hline Sexo & 90 \\
Feminino & 10 \\
Masculino & \\
\hline Escolaridade & 70 \\
Ensino médio incompleto & 30 \\
Ensino médio completo & 70 \\
\hline Classe social & 30 \\
Classe baixa & 20 \\
Classe média & 40 \\
\hline Configuração familiar & 40 \\
Mãe, pai e irmãos (ou não) & \\
Mãe, padrasto e irmãos (ou não) & 40 \\
Mãe e irmãos (ou não) & 60 \\
\hline Acompanhamento Psiquiátrico & 70 \\
Atual ou anterior & 30 \\
Nenhum & \\
\hline Familiar com depressão & \\
Pais, irmãos, tios e/ou avós & \\
Nenhum & \\
\hline
\end{tabular}

Fonte: Autores (2021).

\subsection{Histórico dos sintomas depressivos}

Os adolescentes trouxeram o histórico relacionado aos seus sintomas depressivos, relatando quais os sintomas apresentados, as situações vividas que influenciaram estes sintomas e como foi a busca pelo atendimento na clínica-escola. Seguem abaixo o histórico e as falas dos adolescentes.

Os sintomas trazidos pelos adolescentes foram alteração do sono (insônia ou hipersonia), alteração no apetite (aumento ou diminuição do apetite), irritabilidade, ansiedade, isolamento social, ideação suicida e tentativa de suicídio, sendo que todos relataram comportamentos de autolesão. Como diz ISA15: "Durmo tarde, acordo tarde. Na verdade, eu não tenho muito sono, mesmo se eu dormir, ainda acordo mal [...]. Não tenho muita fome. Sempre fui magra, mas depois, parece que fui piorando". E outras falas: 
"Por algum motivo, sentia muita angústia, quando era menor, e com nove anos eu me mutilava muito [...] eu ficava muito sozinha no quarto, não ia bem na escola e ficava com medo de que algo ruim acontecesse, então eu pegava lâmina de cortador, agulha e me machucava". (SOL17)

"Foi a segunda vez que eu caí no hospital na época. Eu fiquei em 2019, em 2020. Eu tinha tentado (suicídio) outras vezes. Ela (mãe) não imaginava que eu ia pegar os remédios dela [...] e eu pegava a gilete escondida e aí eu acabava fazendo (automutilação) [...] eu tenho insônia desde pequena e instabilidade de humor [...] tinha muita ansiedade [...] falta de apetite”. (EVA18)

Algumas situações vivenciadas, como conflitos familiares, separação dos pais, responsabilidades após o ensino médio, questões de identidade, abuso sexual, gravidez e familiar usuário de drogas, foram citados pelos adolescentes como fatores que motivam ou motivaram as angústias, tristezas e ansiedade sentidas por eles. Como observado nas falas:

“[...] de um tempo para cá eu fui começando a ficar com uns pensamentos diferentes [...], eu começava a me perguntar 'nossa eu estou terminando o ensino médio depois eu vou começar a faculdade, vai ser uma nova fase para mim, o que é que eu vou fazer? '[...]'. (MEL18)

"Acho que é válido comentar que o meu maior problema em relação aos sintomas foi a questão mesmo da minha sexualidade. Quando a minha família descobriu, no momento em si, eu tive esses pensamentos (suicidas) [...] Só que aí, com o tempo, foi se desenvolvendo para outras áreas [...]. Eu fui tendo tipo [...], eu não sei explicar mais ou menos, mas foi tipo um sintoma de desrealização [...]”. (TOM18)

"Quando a minha mãe descobriu (a gravidez), ela passou semanas sem falar comigo, entendeu? [...] fiquei uns dias fora [...] e ela ameaça chamar a polícia, porque eu sou menor de idade. Daí eu tive que voltar, né? [...] Mas antes da gravidez, eu morei com meu pai um ano e pouco com ele [...] por problemas com minha mãe”. (ANA17)

Sobre a busca pelo atendimento psicológico na clínica-escola, alguns adolescentes entrevistados informaram que já tiveram acompanhamento psicológico no início da adolescência, mas a maioria procurou ou foi encaminhada à clínicaescola pela primeira vez, alguns devido à piora dos sintomas durante a pandemia de COVID 19, outros por já terem tentado suicídio. Seguem as algumas falas:

\footnotetext{
"Minha mãe, ela que começou a correr atrás disso para mim, ela começou a se preocupar demais [...] se passasse algo ruim na minha cabeça, eu queria fazer (automutilação) [...] e eles (pais) também não confiavam em me deixar sozinha em casa [...] do médico passou para o CAPS e do CAPS passou para a clínica”. (ISA15)

"Nesse período (da pandemia), eu simplesmente explodi, eu chorava muito, o meu humor estava muito desregulado, sentia raiva e ao mesmo tempo não estava mais conseguindo controlar, eu estava descontando nas pessoas [...] eu nunca tinha feito acompanhamento psicológico, então assim, eu achei que era necessário". (MEL18)

“A primeira vez que eu fui ao psicólogo eu tinha uns 12, 13 anos, por aí. Eu já tinha depressão [...]. Eu acabei conseguindo (consulta na clínica) depois que aconteceu uma situação de eu tentar suicídio [...] eu não lembro quem foi que recomendou, mas a gente foi lá e conseguiu vaga”. (EVA18)
}

\subsection{Benefícios do atendimento psicológico}

Acerca dos benefícios do atendimento psicológico, foram identificadas, nas entrevistas, conforme os relatos dos adolescentes e a partir da análise temática de conteúdo, quatro categorias: aumento da autoestima; benefícios no relacionamento familiar; benefícios durante a pandemia de COVID 19; diminuição/ausência da autolesão e de outros sintomas.

$\mathrm{Na}$ categoria aumento da autoestima, os adolescentes relataram que antes dos atendimentos psicológicos eles se sentiam mais inseguros com relação a algumas questões, como relacionamentos sociais, aparência física e passaram a se aceitar, sentindo-se melhor com eles mesmos. Como na fala de SOL17: “Eu melhorei muito com o tratamento psicológico. 
Antes eu era triste, eu era muito insegura com meu corpo e me ajudou a me aceitar [...] depois que eu fiz o tratamento fiquei muito feliz". E como nas falas de GAL16 e LIS15:

\begin{abstract}
"Mas é realmente isso, tenho conseguido gostar do meu corpo, gostar do que eu gosto de fazer... eu realmente tenho me sentido muito bem e os meus amigos falam que queriam muito ter a minha autoestima [...] meu relacionamento com as outras pessoas têm ficado melhor”. (GAL16)

"Agora eu estou no meu curso (pré-vestibular), eu fiz algumas amizades lá, e a agora eu tenho um grupo com as minhas amigas, com os meus amigos de lá, que a gente é super aberto [...]. E eu até converso com algumas amigas minhas e eu recomendo de verdade fazer terapia”. (LIS15)
\end{abstract}

$\mathrm{Na}$ categoria benefícios no relacionamento familiar, os adolescentes destacaram uma mudança positiva, citando uma melhor comunicação com a família e uma aproximação que antes não era comum. Seguem as falas de MEL18 e SOL17:

"Eu sempre tive esse problema de conversa [...], mas até que agora os meus pais já falaram que viram essa diferença, eu estou muito mais comunicativa, a gente está muito mais próximo. Antes ela (a mãe) simplesmente chegava em casa falava um oi e ia para o quarto, agora não, a gente sai mais [...], então a gente está em um relacionamento muito melhor". (MEL18)

“Com certeza, minha mãe me ajuda muito, a gente conversa muito depois que fiz o tratamento, [...] a gente não conversava [...], a gente conversa bastante, se diverte, sempre assiste filme juntas, os livros que eu leio, sempre conto para ela, ela gosta de me ver lendo, de me ver pintando". (SOL17)

Na categoria beneficios durante a pandemia de COVID 19, os adolescentes afirmaram que houve uma melhora na motivação para a realização de atividades novas em suas rotinas, ou mesmo de atividades que não realizavam mais, além da motivação para o retorno à escola. Como na fala de GAL16: “E como eu voltei (para a escola), e estudo o dia todo, então fico o dia inteiro com as pessoas e está sendo legal. Achei que não seria legal voltar a ver gente, só que está sendo muito legal [...]”. E como nas falas de MEL18 e LIS15:

"Com a chegada do COVID, o isolamento social, foram muitas mudanças para mim, mas após a terapia, eu comecei a ficar mais ativa ao invés de ficar simplesmente deitada na cama [...] eu comecei a fazer qualquer coisa assim: a fotografar; a desenhar; a pintar; cozinhar, a fazer coisas mais produtivas". (MEL18)

“Eu comecei a ler, porque eu queria ter um hobby, ai eu falei: 'Eu quero começar a ler o Harry Potter', porque eu tinha aqui em casa há muito tempo [...] e eu também fiz exercícios (físicos) e quando voltaram as aulas eu já estava um tempo na terapia, [...] quando eu voltei, eu já estava animadona [...]”. (LIS15)

$\mathrm{Na}$ categoria diminuição/ausência da autolesão e de outros sintomas, os adolescentes relataram uma melhora em alguns sintomas como insônia, ansiedade, irritabilidade e sentimento de tristeza. Como na fala de GAL16: "[...] porque às vezes eu fico muito agressiva por conta da minha relação com minha família [...] e eu realmente tendo a ser bem agressiva [...] e estou melhorando, treinando fazer respiração e a me controlar”. E na fala de MEL18:

"[...] depois que eu conversei sobre aquilo com a psicóloga, então tudo aquilo que eu carregava nas costas foi saindo aquele peso, aquela tristeza, aquela dor, então, assim, a conversa me fez muito bem, ver que alguém realmente podia me ajudar. [...] Em relação ao sono e ao apetite eu fui voltando ao normal depois dessas consultas, aí foi quando eu comecei a desapegar mais do remédio”. (MEL18)

E sobre automutilação, os adolescentes trouxeram um maior autocontrole sobre esse comportamento. Como relatam 
“[...] só que antes, eu não fazia nada para mudar isso. Eu geralmente me cortava mesmo, mas quando eu comecei o atendimento, ele me sugeriu que eu escrevesse e eu comecei a escrever [...] melhorou um pouco [...] geralmente a coisa fica remoendo na minha cabeça, aí para organizar, eu escrevo". (BIA16)

"[...] porque naquela época eu não estava nem aí; se naquela época eu tivesse que morrer, eu não estava nem aí [...] Aí da primeira vez que eu fiz (cortes), ele (pai) descobriu e quis me levar (clínica-escola), entendeu? Desde aí, eu nunca mais quis fazer [...] E graças a Deus eu só senti os sintomas melhorarem. Não voltei a sentir mais ". (LUA15)

\section{Discussão}

Acerca da predominância do sexo feminino, o Manual Diagnóstico e Estatístico de Transtornos Mentais-DSM-5 (APA, 2014) aponta uma disparidade relevante da perturbação depressiva de adolescentes do sexo feminino em relação ao sexo masculino. Foi identificado, entre os adolescentes que estavam no ensino médio, predomínio de sintomas depressivos e de ansiedade no sexo feminino, o que torna importante a consideração desta variável (Germain \& Marcotte, 2016; Grolli et al, 2017). Além disso, pode haver também maior resistência masculina à intervenção ou busca por ajuda psicológica (Gonçalves, 2016).

O histórico familiar de depressão é considerado um fator de risco para a presença de sintomas depressivos nos adolescentes, além da influência das questões biopsicossociais (Müller \& Silva, 2017). E nessa pesquisa, os participantes trouxeram questões como conflitos familiares, responsabilidades, busca da identidade, abuso sexual e gravidez como alguns dos motivos de seus sofrimentos. Sendo assim, faz-se necessário compreender que as variáveis isoladamente não retratam fatores de risco ou proteção para a depressão na adolescência, mas se deve buscar um olhar amplo acerca da constituição destes como indivíduos (Grolli et al, 2017).

Além disso, situações adversas como a pandemia de COVID 19, que trouxe uma mudança de rotina com o isolamento social, afetam a população de várias formas, tanto física como psicologicamente (Oliveira et al, 2020). Os adolescentes, que estão em uma fase de maior interação social com grupos externos à família, também se sentem afetados emocionalmente com essas mudanças (Oliveira et al, 2020). Pode-se citar como fatores de risco ao adoecimento dos adolescentes nessa situação de pandemia: aumento do sedentarismo, mudanças na rotina de alimentação e do sono, práticas como fumo e ingestão de álcool (Miliauskas \& Faus, 2020; Stanton et al, 2020).

Neste contexto, as ações direcionadas ao atendimento em saúde mental são importantes no cuidado dos adolescentes com algum tipo de transtorno psicológico, como a depressão, e esses serviços se tornam ainda mais necessários na prevenção da piora de sintomas pré-existentes ou do adoecimento no período de pandemia (Miliauskas \& Faus, 2020). Isso porque o indivíduo com sintomas depressivos não se considera importante, atraente, acreditando ter pouca ou nenhuma chance de um bom futuro, seja profissional, seja pessoal, e realiza interpretações negativas sobre eventos diversos, alimentando-se de pensamentos e sentimentos ruins (Beck, 2013, Grolli et al, 2017). O acompanhamento psicológico realizado por profissional da área de psicologia configura-se como um dos importantes caminhos para o atendimento dessa demanda. Como na fala de LUA15: "Se eu não tivesse tido eles me acompanhando direto, eu acho que teria acontecido algo pior comigo. Os meus sintomas poderiam ter aumentado [...] então, eu acredito que é importante ter essa parceria com eles".

Verificam-se também, nesta pesquisa, relatos de crises de ansiedade juntamente com sintomas de depressão, como na fala de ANA17: "Eu tenho crise de ansiedade e eu tive um quadro muito grave de depressão antes de ter a minha gravidez. Acho que eu tenho essas situações assim de depressão e ansiedade desde os meus 14 anos, eu acho”. As pessoas que apresentam um quadro de depressão também podem ser acometidas pela ansiedade patológica, com a presença de crises ansiosas em algumas situações, sendo as características de ambos os transtornos levados em consideração no diagnóstico médico do paciente (Rós et al, 2020; Tiller, 2013). 
Com o acompanhamento psicológico muitos participantes relataram a diminuição de comportamentos como a automutilação ou mesmo a tentativa de suicídio como resultado do entendimento de suas angústias e da busca por novos sentidos em suas vidas. A ideação suicida trazida nos relatos dos adolescentes são pensamentos de morte, uma idealização de uma existência sem sofrimento, porém os adolescentes podem ir além das ideias e tentar o suicídio através de ingestão de medicamentos, automutilação, se colocar em situação de perigo, podendo chegar à morte (Braga \& Dell'Aglio, 2013; Müller \& Silva, 2017). Como diz SOL17: "Eu sentia muita dor, me sentia sozinha [...] eu não sabia explicar, não sabia na verdade que aquilo era automutilação e que en estava ruim por algum motivo, mas algo que eu fazia aliava, então continuei".

Acerca do trabalho psicoterápico, a psicóloga Vera Vital Brasil afirma que: “[...] o reconhecimento das fontes de produção de angústia, medo e sofrimento poderá permitir a criação de novos sentidos [...] dar lugar a novos modos de funcionamento psíquico" (Felicidade, Medo e Depressão, 2017, p. 23). E ainda, segundo a psicóloga Maria Thereza dos Santos, "a clínica psicológica não se caracteriza somente pelo espaço onde é realizada, mas antes pela escuta e pelo acolhimento oferecidos ao sujeito" (Felicidade, Medo e Depressão, 2017, p. 22). Segue a fala de MEL18 sobre o atendimento psicoterápico: "[...] quando eu procurei ela, foi simplesmente como abrir uma porta para mim e começar um novo caminho. Eu comecei a falar de todos os meus problemas [...] Eu tirei o meu lado mais secreto e falei para ela”.

$\mathrm{Na}$ psicoterapia, o profissional busca compreender o paciente de forma ampla e sem julgamentos, atuando como intermediador do paciente para que este tenha um outro olhar sobre suas próprias vivências, caminhando, assim, para a mudança do estado de sofrimento (Perches, 2021). Como nessa fala de BIA16: "Depois que eu comecei a ir, eu comecei a ver as coisas de um outro ângulo. Então, foi bem melhor".

Além disso, percebeu-se nas falas de alguns participantes desta pesquisa motivação em procurar ajuda, tendo um comprometimento com o tratamento psicológico, o que pode ter contribuído para os benefícios relatados por eles. Como na fala de TOM18: "Eu já tinha uma ideia de como funcionava a psicologia e tudo mais. Eu já tinha pesquisado bastante sobre o que realmente eu estava querendo. Eu fui atrás. Não tive, por exemplo, família me colocando lá”.

Destacam-se, também, neste estudo, os relatos dos participantes acerca da melhora no convívio familiar nessa busca por ajuda aos seus problemas. Dessa forma, as situações de crise na adolescência, como a tentativa de suicídio, a autolesão, podem trazer mudanças no relacionamento familiar, com uma aproximação dos membros da família com o adolescente, maior compreensão, empatia, preocupação e cuidados. (Ferigato, et al, 2007; Rossi \& Cid, 2019). Essas transformações trazem benefícios para o adolescente, o que demonstra o papel essencial da família no processo de atenção em saúde mental de adolescentes, contribuindo no fortalecimento e no enfrentamento da situação (Moura, 2018; Rossi \& Cid, 2019). Além disso, quando as relações intrafamiliares trazem segurança e confiabilidade entre seus membros, pode-se dizer que estas proporcionam uma proteção à saúde mental, principalmente quando se trata de crianças e adolescentes, o que torna importante o olhar e cuidados às famílias (Oliveira et al, 2020; Rossi et al, 2019).

O tratamento para os que apresentam sintomas depressivos é amplo, devendo-se considerar todos os aspectos que influenciam esse estado, envolvendo as questões sociais, biológicas e psicológicas na individualidade dessas pessoas, o que pode incluir tanto a clínica-médica, quanto a clínica-psicológica (Rocha et al, 2016). Nesse sentido, a Organização Mundial da Saúde indica conciliar as intervenções medicamentosas e psicoterápicas (Rocha et al, 2016; WHO, 2012).

Em relação à área de atendimento social e de saúde, tendo como exemplo nessa pesquisa a clínica-escola, a Organização Mundial de Saúde destaca a importância desses serviços no tratamento e prevenção dos sintomas depressivos na população (Pinto et al, 2018; WHO, 2013). A clínica-escola é porta de entrada que permite aos usuários serem acolhidos e entendidos em suas necessidades (Rocha et al, 2016; Santeiro et al, 2013). Além disso, sabe-se que as clínicas-escola beneficia a população através dos atendimentos acessíveis oferecidos à comunidade (Fam \& Neto, 2019; Honda \& Yoshida, 2012). 
A Psicologia traz um olhar para além da doença, buscando uma abordagem voltada para a subjetividade do indivíduo (Pinto et al, 2018; Seligman \& Csikszentmihalyi, 2014). Neste sentido, a psicologia se volta a uma mudança de visão das vivências do sujeito e que podem estar gerando sofrimento psíquico, fazendo com que o indivíduo caminhe para a direção do seu bem-estar diante do contexto em que vive (Pinto et al, 2018; Seligman \& Csikszentmihalyi, 2014). Sobre a importância do tratamento dos sintomas depressivos, GAL16 diz: "Eu acho muito importante porque, principalmente agora que estou na minha transição de jovem para adulta, é importante porque se eu não estivesse procurado ajuda, eu acabaria arrastando isso para minha vida adulta".

Esta pesquisa, que não foi voltada apenas para os pacientes com diagnóstico de depressão, mas também para aqueles que apresentavam sofrimento psicológico com sintomas depressivos, apresenta resultados relevantes quanto aos benefícios do atendimento psicoterápico. Esses benefícios subjetivos relatados podem estar mais voltados a situações externas, como as relações familiares, escolares e atividades do dia a dia. Mesmo com esses avanços, eles não significam a eliminação completa dos sintomas depressivos. No entanto, muitos participantes demonstraram em seus relatos uma significativa alteração de hábitos que melhoraram o estilo e qualidade de vida com a minimização dos sintomas.

\section{Considerações Finais}

Sabe-se que os sintomas depressivos podem trazer consequências negativas para a população de forma geral e, no que diz respeito aos adolescentes, isso se torna mais preocupante devido às mudanças biopsicossociais relacionadas a essa fase. Esse fato demonstra a importância de serviços de saúde mental que atendam a demanda desse público específico. Além disso, esses serviços tornam-se ainda mais relevantes em situações de mudanças extremas, como o contexto vivido durante a pandemia de Covid-19, que trouxe um impacto na vida da população mundial em vários aspectos, inclusive psicológico.

Dessa forma, com a realização desta pesquisa, foi possível identificar os benefícios do atendimento psicológico na visão dos adolescentes que procuraram atendimento em uma clínica-escola, alcançando, assim, o objetivo proposto neste estudo. Os benefícios foram possíveis de evidenciar através dos relatos dos participantes acerca da própria percepção das melhorias em alguns aspectos do dia a dia, nos relacionamentos sociais e familiares e na melhoria de alguns sintomas como irritabilidade, ansiedade, alterações no apetite e no sono. Nesse sentido, este estudo servirá de base para pesquisas futuras, podendo contribuir para uma discussão acerca da importância do apoio a esse público com características próprias e que traz uma demanda significativa no que diz respeito à saúde mental, envolvendo um crescente número de transtornos mentais e suicídio nessa fase da vida.

Ainda, com os resultados obtidos nesta pesquisa, foi possível perceber a necessidade de se investigar de forma mais ampla o contexto no qual os adolescentes estão inseridos, com a inclusão de outros participantes nos estudos, como a família, a escola e o próprio profissional que realizou o atendimento do adolescente, com intuito de entender acerca dos fatores que influenciam o sofrimento psíquico deste e as melhorias percebidas por diversos olhares, não só a percepção do adolescente. E, também, verificou-se a necessidade de acolher adolescentes do sexo masculino, visto que existe um número reduzido na procura de serviços de saúde mental por parte destes, dificultando a identificação do sofrimento psíquico e o tratamento desse público.

\section{Referências}

American Psychiatric Association. (2014). Manual Diagnóstico e Estatístico de Transtornos Mentais (5a ed). Artmed.

Beck, J. S. (2013). Terapia cognitiva: teoria e prática. Artmed. https://oitavaturmadepsicofm.files.wordpress.com/2019/03/terapia-cognitiva-teoria-eprc3a1tica.-judith-beck.pdf. 
Benetti, S. P. C., Mattos, C. V., Silva, N. B., \& Bittencourt, A. (2017). A. Avaliação de processo em psicoterapia psicanalítica na adolescência. Psico, 48(2), 130-139. https://doi.org/10.15448/1980-8623.2017.2.24820

Bonin, L., \& Moreland, C. S. (2012). Overview of prevention and treatment for pediatric depression. Uptodate. https://www.uptodate.com/contents/overviewof-preventionand-treatment-for-pediatric-depression?search=Overview $\% 20 \mathrm{of} \% 20$ treatment $\% 20$ for $\% 20$ adolescent $\% 20 \mathrm{depression} \&$ source=search_re sult\&selectedTitle=1 150\&usage_type=default\&display_rank=1

Braga, L. L., \& Dell'Aglio, D. D. (2013). Suicídio na adolescência: fatores de risco, depressão e gênero. Contextos Clínicos, 6(1), 2-14. http://dx.doi.org/10.4013/ctc.2013.61.01

Brito, C. N. O., Alves, S. V., Ludermir, A. B., \& Araújo, T. V. B. (2015). Depressão pós-parto entre mulheres com gravidez não pretendida. Revista de Saúde Pública, 49(33), 1-9. https://doi.org/10.1590/S0034-8910.2015049005257

Cordioli, A. V., Alves, L. P. C., Valdivia, L., \& Rocha, N. S. (2018). As principais psicoterapias: fundamentos teóricos, técnicas, indicações e contraindicações. In A. V. Cordioli, \& E. H. Grevet, (Orgs.), Psicoterapias: Abordagens atuais. (4a ed., pp. 64-95). Artmed.

Fam, B. M, \& Neto, J. L. F. (2019). Análise das Práticas de uma Clínica-Escola de Psicologia: Potências e Desafios Contemporâneos. Psicologia: Ciência e Profissão, 39, e178561, 1-16. http://dx.doi.org/10.1590/1982-3703003178561

Felicidade, Medo e Depressão: O Brasil em tempos sombrios: o que a psicologia tem a dizer sobre isso? (2017). Jornal do Conselho Regional de psicologia do Rio de Janeiro, 12 (44)18-23. http://www.crprj.org.br/site/wp-content/uploads/2017/10/jornal44.pdf.

Ferigato, S. H., Campos, R. O., \& Ballarin, M. L. (2007). O atendimento à crise em saúde mental: ampliando conceitos. Revista de Psicologia da UESP, 6(1), 31-44. https://www.fcm.unicamp.br/fcm/sites/default/files/paganex/sabrinaferigato2007oatendimentoacrise.pdf.

Galhardi, C. C., \& Matsukura, T. S. (2018). O cotidiano de adolescentes em um Centro de Atenção Psicossocial de Álcool e outras drogas: realidades e desafios. Cadernos de Saúde Pública, 34(3), 1-12. https://doi.org/10.1590/0102-311X00150816

Germain, F., \& Marcotte, D. (2016). Sintomas de depressão e ansiedade na transição do ensino secundário ao ensino médio: evolução e fatores influentes. Revista adolescência \& saúde, 13(1), 19-28. https://pesquisa.bvsalud.org/portal/resource/pt/abr-593

Gonçalves, L. O., Farinha, M. G., \& Goto, T. A. (2016). Plantão psicológico em unidade básica de saúde: atendimento em abordagem humanistafenomenológica. Revista da Abordagem Gestáltica, 22(2), 225-232. http://pepsic.bvsalud.org/scielo.php?script=sci_arttext\&pid=S1809$68672016000200015 \& \operatorname{lng}=$ pt\&nrm=isso

Grolli, V., Wagner, M., \& Dalbosco, S. P. (2017). Sintomas de depressão e de ansiedade em adolescentes do ensino médio. Revista de Psicologia da IMED, 9 (1), 87-103. http://dx.doi.org/10.18256/2175-5027.2017.v9i1.2123

Henriques, A. A. C. (2018). Clima familiar e sintomatologia ansiosa e depressiva em adolescentes: Qual o papel da resiliência? [Dissertação de Mestrado], Universidade Lusófona de Humanidades e Tecnologias. http://recil.grupolusofona.pt/handle/10437/8812

Honda, G., \& Yoshida, E. (2012). Mudança em pacientes de clínica-escola: Avaliação de resultados e processos. Paidéia, 22(51):73-82. https://doi.org/10.1590/S0103-863X2012000100009

Just, A. P., \& Enumo, S. R. F. (2015). Problemas emocionais e de comportamento na adolescência: o papel do estresse. Boletim Academia Paulista de Psicologia, 35(89), 350-370. http://pepsic.bvsalud.org/scielo.php?script=sci_arttext\&pid=S1415-711X2015000200007

Lei n 8.069 de 13 de julho de 1990. (1990, 16 julho). Dispõe sobre o Estatuto da Criança e do Adolescente (ECA) e dá outras providências. Diário Oficial da União, Brasília, DF.

Lemgruber, V. B. Terapia Focal: psicoterapia breve psicodinâmica. (2008). In A. V. Cordioli, (Org.), Psicoterapias: Abordagens atuais. (3a ed., pp. 167-187). Artmed.

Miliauskas, C. R., \& Faus, D. P. (2020). Saúde mental de adolescentes em tempos de COVID-19: desafios e possibilidades de enfrentamento. Physis: Revista de Saúde Coletiva, 30(4), e300402. http://dx.doi.org/10.1590/S0103-73312020300402

Minayo, M. C. S. (2014). O desafio do conhecimento: Pesquisa qualitativa em saúde. (14a ed.). Hucitec-Abrasco.

Moura, B. R. (2018). A atenção à crise nos centros de atenção psicossocial infantojuvenis [Dissertação de Mestrado], Universidade Federal de São Carlos. https://repositorio.ufscar.br/bitstream/handle/ufscar/10081/CARTA\%20REPOSIT\%c3\%93RIO.pdf?sequence=2\&isAllowed=y

Müller, R. M., \& Silva, J. (2017). Depressão e suicídio no adolescente na clínica psicanalítica: um estudo de caso. Boletim Entre SIS, 2(2), 55-69. https://online.unisc.br/acadnet/anais/index.php/boletimsis//article/view/17676/4551

Oliveira, W. A., Silva, J. L., Andrade, A. L. M., Micheli, D., Carlos, D. M., \& Silva, M. A. I. (2020). A saúde do adolescente em tempos da COVID-19: scoping review. Caderno de Saúde Pública, 36(8), e00150020. https://doi.org/10.1590/0102-311X00150020

Organización Mundial de la Saúde (2002). Saúde mental: nova concepção, nova esperança. Relatório Mundial da Saúde da OMS. https://www.who.int/whr/2001/en/whr01_djmessage_po.pdf.

Organización Mundial de la Saúde (2016). Prevención de la conducta suicida. Washington: Organización Panamericana de la Salud. http://iris.paho.org/xmlui/bitstream/handle/123456789/31167/9789275319192-spa.pdf? sequence=1\&isAllowed=y

Organização Mundial de Saúde (2014). Saúde para os adolescentes do mundo. Uma segunda chance na segunda década. http://apps.who.int/adolescent/second-decade/ 
Research, Society and Development, v. 11, n. 2, e50811225980, 2022

(CC BY 4.0) | ISSN 2525-3409 | DOI: http://dx.doi.org/10.33448/rsd-v11i2.25980

Perches, T. H. P., \& Antunez, A. E. A. (2021). Estudo psicológico do processo diagnóstico e da psicoterapia na depressão e na ansiedade por meio da análise fenômeno-estrutural: estudos de caso. Boletim Academia Paulista de Psicologia, 4l(100):1-15. http://pepsic.bvsalud.org/scielo.php?script=sci_arttext\&pid=S1415-711X2021000100002

Pinto, A. V. L., Cavalcanti, J. G., Araújo, L. S., Coutinho, M. L., \& Coutinho, M. P. L. (2018). Depressão e adolescência: relação com qualidade de vida e bem-estar subjetivo. Revista de Psicologia da IMED, 10(2):6-21. http://pepsic.bvsalud.org/scielo.php?script=sci_arttext\&pid=S2175$50272018000200002 \& \operatorname{lng}=$ pt\&nrm=iso

Rocha, M. A. G., Bunge, M., Strauss, V., Honda, G. C. H., Peixoto, E., Santeiro, T. V., \& Espinosa, M. L. (2016). Psicoterapia breve psicodinâmica de caso grave de depressão em serviço-escola: limites e alcance. Contextos Clínicos, 9(1), 86-97. http://dx.doi.org/10.4013/ctc.2016.91.07

Rós, I. A., Ferreira, C. A. C., \& Garcia, C. S. (2020). Avaliação da Psicoterapia de Grupo em Pacientes com Ansiedade e Depressão. Revista Psicologia e Saúde, 129(1), 75-86. http://dx.doi.org/10.20435/pssa.v12i1.830

Rossi, L. M., \& Cid, M. F. B. (2019). Adolescências, saúde mental e crise: a história contada por familiares. Cadernos Brasileiros de Terapia Ocupacional, 27(4), 734-742. http://www.scielo.br/scielo.php?script=sci_arttext\&pid=S2526-89102019000400734\&lng=en\&nrm=iso\&tlng=pt

Rossi, L. M., Marcolino, T. Q., Speranza, M., \& Cid, M. F. B. (2019). Crise e saúde mental na adolescência: a história sob a ótica de quem vive. Caderno de Saúde Pública, 35(3), e00125018. https://doi.org/10.1590/0102-311X00125018

Santeiro, T. V., Rocha, G. M. A., \& Araujo, D. S. A. (2013). Implantação de um serviço-escola de Psicologia no centro-oeste brasileiro: usuários e atendimentos. Perspectivas em Psicologia, 7(2), 65-82. http://www.seer.ufu.br/index.php/perspectivasempsicologia/article/view/28556

Seligman, M. E. P., \& Csikszentmihalyi, M. (2014). Positive Psychology: An Introduction. American Psychologist, 55(1); 5-14.

https://www.scielo.br/j/pcp/a/6NkyXJ9sY4xWvdDRVgBQr3f/abstract/?lang=pt

Silvares, E. F. M. (Org.) (2006). Atendimento psicológico em clínicas-escola. Átomo.

Stanton, R., To, Q.G., Khalesi, S., Williams, S. L., Alley, S. J., Thwaite, T. L., Fenning, A. S., \& Vandelanotte, C. (2020). Depression, Anxiety and Stress during COVID-19: Associations with Changes in Physical Activity, Sleep, Tobacco and Alcohol Use in Australian Adults. International Journal of Environmental Research and Public Health, 17(11), 4065. https://doi.org/10.3390/ijerph17114065

Thapar, A., Collishaw, S., Pine, D. S., \& Thapar, A. K. (2012). Depression in adolescence. The Lancet, 379(9820),1056-67. 10.1016/S0140-6736(11)60871-4

Tiller, J. W. G. (2013). Depression and anxiety. The Medical Journal of Australia, 199(6), 10-29. https://www.mja.com.au/journal/2013/199/6/depression-andanxiety

World Health Organization. (2012). Depression. A Global Public Health Concern Developed by MarinaMarcus, M. Taghi Yasamy, Mark van Ommeren, and Dan Chisholm, Shekhar Saxena. WHO Department of MentalHealth and Substance em:http://www.who.int/mental_health/management/depression/wfmh_paper_depression_wmhd_2012.pdf?ua=1

World Health Organization (2013). Comprehensive mental health action plan 2013-2020. World Health Assembly. http://apps.who.int/gb/ebwha/pdf_files/WHA66/A66_R8-en.pdf?ua=1 